\title{
Going green - treatment outcome and safety profile of chronic central serous chorioretinopathy treated with subthreshold green laser
}

This article was published in the following Dove Press journal:

Clinical Ophthalmology

\author{
Anadi Khatri' \\ Eli Pradhan ${ }^{2}$ \\ Sweta Singh' \\ Roshija Rijal' \\ Bal Kumar Khatri ${ }^{3}$ \\ Gyanendra Lamichhane' \\ Muna Kharel ${ }^{4}$ \\ 'Department of Retina, Lumbini Eye \\ Institute, Lumbini, Nepal; '2Department \\ of Retina, Tilganga Institute of \\ Ophthalmology, Kathmandu, Nepal; \\ ${ }^{3}$ Department of Ophthalmology, \\ Birat Eye Hospital, Biratnagar, Nepal; \\ ${ }^{4}$ Department of Ophthalmology, \\ Nepalese Army Institute of Health \\ Sciences, Kathmandu, Nepal
}

\begin{abstract}
Aim: Subthreshold lasers have gained popularity in the treatment of chorioretinopathy central serous chorioretinopathy (CSCR) and yellow $(577 \mathrm{~nm})$ lasers have completely revolutionized the treatment. However, there is very little literature regarding the use of a more common and conventional - green $(532 \mathrm{~nm})$ subthreshold laser for the treatment of chronic CSCR. We report the use of green $(532 \mathrm{~nm})$ laser for the treatment of chronic CSCR and its outcome.
\end{abstract}

Methods: Eyes with nonresolving CSCR were treated with green subthreshold laser and evaluated at the end of 5 months. Visual acuity, central macular thickness (CMT), and macular volume (MV) at baseline and at 5 months following treatment were evaluated.

Results: Thirteen eyes with chronic CSCR were treated with green laser in SP-Mode ${ }^{\mathrm{TM}}$. The mean duration of CSCR was $7.64 \pm 3.77$ months at the time of treatment. The median age of the patients was 41 (35-57) years. The baseline mean best-corrected visual acuity (BCVA) was $0.96 \operatorname{logMAR} \pm 0.17$, with mean baseline CMT of $503.8 \mu \mathrm{m} \pm 181.9$ and MV of $12.8 \mathrm{~mm}^{3} \pm$ 3.81. The mean CMT at 5 months was $211 \mu \mathrm{m} \pm 31.7$ and mean MV was $9.65 \mathrm{~mm}^{3} \pm 0.60$, correlating to a mean decrease of $292 \mu \mathrm{m} \pm 79$ in CMT and mean decrease of $3.18 \mathrm{~mm}^{3} \pm 1.87$ in the MV from baseline $(P<0.05)$. The mean BCVA after treatment was $0.18 \log \mathrm{MAR} \pm 0.09$ $(P<0.05)$. Two cases of CSCR with pigment epithelial detachment (PED) also had complete resolution of both at 5 months.

Conclusion: Subthreshold green laser $(532 \mathrm{~nm})$ is a safe and effective modality for the treatment of chronic CSCR with very good and stable outcomes. It may also be beneficial in the treatment of PEDs.

Keywords: CSCR, green laser, subthreshold, $532 \mathrm{~nm}$, PED

\section{Introduction}

Central serous chorioretinopathy (CSCR) is an idiopathic retinal pathology where a collection of fluid occurs around or inside the vascular arcades of the retina. It often causes a well-demarcated serous detachment of the retina and has a propensity to the macular and the perifoveal region. ${ }^{1}$

The exact mechanism of this pathology still remains a subject of debate. There are various theories ranging from intraretinal pigment epithelial imbalance of electrolyte homeostasis to increased hydrostatic forces in the choroidal circulation. ${ }^{2}$

Many risk factors have also often been associated with the use of corticosteroids and stress or type A personality often being the most concomitant..$^{3-5}$
Correspondence: Anadi Khatri

Department of Retina, Vitreo Retina Fellow, Lumbini Eye Institute, PO Box No 30, Siddhartha Nagar-3, Rupandehi 3290I, Lumbini Zone, Nepal

$\mathrm{Tel}+977$ | 4 I। 2600

Fax +977984I76 7205

Email anadikc@gmail.com 
CSCR is usually self-limiting with prognosis often regarded from very good to excellent. Significant vision gain is often gained in most of the patients in a duration of 3-6 months. ${ }^{6,7}$

Unfortunately, it has been reported that as much as 50\% of cases can have recurrences and nearly $15 \%$ cases may have a chronic CSCR. ${ }^{8-10}$

Existing treatment modalities include conventional laser photocoagulation and photodynamic therapy and recent subthreshold lasers. ${ }^{11}$ However, the treatment still remains a controversy.

Chronic or nonresolving CSCR often results in permanent disorganization in the retinal elements. These can range from retinal thickening, cystoid changes to loss of photoreceptor loss. When the pathology takes this course, the recovery of visual acuity is usually limited. ${ }^{12,13}$

The duration to qualify a CSCR as chronic still remains a subject of debate. It ranges from 3 to 6 months in various studies with no discrete agreement. Majority of the previous researches have used CSCR persisting for 3 months to define "chronic". We have also used the same criteria. ${ }^{14,15}$

We treated patients with worsening visual acuity secondary to CSCR or in patients with chronic/nonresolving CSCR.

Various results have been reported on patients with chronic CSCR who were treated with subthreshold lasers and micropulse lasers. ${ }^{16-19}$

Subthreshold lasers offer the precision and limited collateral damage to the surrounding tissue by confining the thermionic effect only to the retinal pigment epithelium (RPE) layer ${ }^{20}$ The energy is divided into multiple "packets," causing limited and often nonlethal temperature rise. ${ }^{21}$

Now with the introduction of the yellow $(577 \mathrm{~nm})$ lasers, the treatment has taken us closer to fovea than ever before. It spares the xanthophyll, which is found in the plexiform layers, causing minimal damage to the neuroretinal layer. ${ }^{15,22}$

Recently, a more in-depth understanding of the Arrhenius integral $(\Omega)$ has started becoming a game changer in laser therapy in ophthalmology. $\Omega$ identifies sublethal thermal values, which are predetermined using experiments on heat shock protein expression following sublethal retinal exposures. ${ }^{23}$

For $\Omega<0.1$, there is very little effect or damage to the cells, while cells with $\Omega>1$ are at risk of being irreversibly damaged. The same model, when applied to micropulse or subthreshold modules, also demonstrates that continuous wave laser treatment of the same duration and same average power produces a similar average temperature and Arrhenius integral. This implies that micropulsing may not be actually necessary and that similar tissue effects can be produced using more conventional continuous wave lasers, as long as power and duration are appropriately controlled. ${ }^{24}$

Arrhenius integral has previously already been used to provide an algorithm for Endpoint Management (TOPCON) in their Pattern Scan Laser (PASCAL) system. Various other laser systems have also started adopting the algorithm and have equipped their lasers of green $(532 \mathrm{~nm})$ spectrum with subthreshold potentials. ${ }^{11,24}$

In this article, we report the use of green subthreshold laser in the treatment of chronic CSCR and its outcomes. We also intend to highlight the role, efficacy, and prospect of the green subthreshold laser in the laser retinal therapy for chronic CSCR. We also report a unique set of subthreshold parameters used for the treatment.

\section{Methods}

This is a prospective noncomparative consecutive interventional case series performed at Lumbini Eye Institute, Lumbini, Nepal, from December 2017 to June 2018. Thirteen eyes of 12 patients were enrolled in this interventional prospective study. The research has been approved by the ethics committee and the institutional review board of Lumbini Eye Institute, Lumbini, Nepal, and has adhered to the tenets of the Declaration of Helsinki. Written informed consent was obtained from each patient enrolled for the treatment. This study adheres to the tenets of the Declaration of Helsinki. Inclusion criteria included adults $\geq 18$ years old. Nonresolving CSCR was defined as persistent CSCR with a duration of 3 months or more; best-corrected visual acuity (BCVA) 6/36 or worse in the study eye; and presence of active angiographic leakage in fluorescein angiography (FA). Optical coherence tomography (OCT) of the macula was also done to identify the leakage area using a retinal map. Exclusion criteria included any previous treatment for CSCR in the study eye including the use of anti-VEGFs, subfoveolar leak, patients currently under oral/topical steroid therapy for any systemic cause, decrease in visual acuity due to other retinal pathology, history of intraocular surgical intervention in the study eye, prior laser photocoagulation therapy of any kind in the study eye, or contraindications for fluorescein dye.

All participants underwent a comprehensive ophthalmic examination including BCVA testing, slit-lamp biomicroscopy, intraocular pressure measurement using Goldmann applanation tonometer, and dilated fundoscopic examination. 
Color fundus photography, FA and OCT was performed at baseline using Zeiss VISUCAM 524 and Zeiss Cirrus HD OCT 5000. The scans included a 5-line raster scan pattern for quantifying the central macular thickness (CMT) and macular volume (MV).

A single retinal specialist $(\mathrm{AK})$ performed the treatment planning FA images and retinal thickness mapping to identify the leaking point. The laser system used was Lightmed LIGHTLas 5322.0 console, which is a continuous wave laser system that is equipped with SP-Mode ${ }^{\mathrm{TM}}$ technology, which also allows setting for micropulse delivery. The laser treatment was done using the same device using Area Centralis Volk ${ }^{\mathrm{TM}}$ lens. Initial test burn was performed at the superotemporal arcade. The energy was set to $100 \mathrm{~mW}$ initially and titrated by $10 \mathrm{~mW}$ until grayish white burn (grade 3 laser burn) with a spot size of $100 \mu \mathrm{m}$ and pulse duration of 0.2 seconds. One hundred percent of the power and duty cycle of $10 \%$ using SP-Mode (minimal-subthreshold) $(1,800 \mu$ s off and $200 \mu \mathrm{s})$ was used. Multiple confluent but nonoverlapping spots were placed over areas of focal and diffuse RPE leak. Besides the leak point, we treated the area approximately five to six spots around the leak points in areas of fluid collection sparing approximately one laser spot in all direction from the fovea. Ninety-five to 100 spots for an area approximately corresponding to a disc diameter were used in cases of diffuse leaks.

We confirm that all regulations concerning the ethical use and safety of human volunteers were strictly followed during this research. The primary outcome measure was a degree of resolution of neurosensory detachment (NSD) at 5 months of follow-up on SD-OCT after laser therapy. Secondary outcome measures included a change in BCVA score and change in $\mathrm{MV}$ at follow-up at fifth month compared with baseline.

\section{Statistical analysis}

Descriptive statistics were calculated for each variable. Visual acuity was converted to logMAR (the logarithm of the minimum angle of resolution) for statistical analysis. Statistical analyses were done using SPSS software (version 20.0). To analyze the change in CMT, MV, and BCVA at baseline and at 3-month follow-up, paired Student's $t$-test was used. A $P$-value of 0.05 was considered statistically significant.

\section{Ethical approval}

The research has been approved by the ethics committee and the institutional review board of Lumbini Eye Institute, Lumbini, Nepal, and has adhered to the tenets of the Declaration of Helsinki.

\section{Results}

A total of 13 eyes of 12 patients with a diagnosis of chronic CSCR were recruited and treated with a single session of green laser in SP-Mode. All of them had a history of CSCR of $>3$ months with a mean duration of $7.64 \pm 3.77$ months at the time of treatment. All patients were male. The median age of the patients was 41 (35-57) years. All patients were evaluated before receiving laser treatment, and their baseline parameters were recorded. Their presenting mean BCVA was $0.96 \log M A R \pm 0.17$. They had a mean baseline CMT of $503.8 \mu \mathrm{m} \pm 181.9$ and MV of $12.8 \mathrm{~mm}^{3} \pm 3.81$ (Table 1).

All patients were treated only once with laser and were evaluated for endpoint response at 5-month follow-up. The power of the laser that we used ranged from 120 to $200 \mathrm{~mW}$. The rest of the laser parameters used were uniform in all patients. SP-Mode was used with a duty cycle of $10 \%$.

The median number of burns placed was 76 (48-179). The mean CMT at 5-month follow-up was $211 \mu \mathrm{m} \pm 31.7$ and mean MV was $9.65 \mathrm{~mm}^{3} \pm 0.60$. This correlated with a mean decrease of $292 \mu \mathrm{m} \pm 79$ from the baseline in CMT and mean decrease of $3.18 \mathrm{~mm}^{3} \pm 1.87$ in the MV. There was a mean BCVA gain of 3.91 \pm 0.98 lines. The mean BCVA after treatment was $0.18 \log M A R \pm 0.09$. Table 2 summarizes the study data of the patients, and representative cases are illustrated in Figures 1-4.

Table I Pretreatment and post-treatment measured parameters

\begin{tabular}{l|l|l|l|l}
\hline & Baseline & At I month & At 3 months & At 5 months \\
\hline Visual acuity (logMAR) & & & & \\
$\quad$ Mean & 0.96 & 0.61 & 0.22 & 0.18 \\
$95 \% \mathrm{Cl}$ for mean $P<0.05$ & $0.86-1.06$ & $0.73-0.98$ & $0.32-0.56$ & $0.12-0.23$ \\
$\begin{array}{l}\text { Central macular thickness }(\mu \mathrm{m}) \\
\text { Mean }\end{array}$ & 503 & 412 & 291 & 211 \\
$95 \% \mathrm{Cl}$ for mean $P<0.05$ & $398-608$ & $296-547$ & $231-492$ & $193-230$ \\
Macular volume $\left(\mathrm{mm}^{3}\right)$ & & & & \\
$\quad$ Mean & 12.8 & 11.2 & 10.7 & 9.65 \\
$95 \% \mathrm{Cl}$ for mean $P<0.05$ & $11.7-17.3$ & $9.8-16.5$ & $9.1-13.5$ & $9.1-10.2$ \\
\hline
\end{tabular}


Table 2 Change in measurable parameters when compared with baseline findings at 5-month follow-up

\begin{tabular}{l|l}
\hline Parameters & Values \\
\hline Change in central macular thickness $(\mu \mathrm{m})$ & \\
Mean & 292 \\
$95 \% \mathrm{Cl}$ for mean $P<0.05$ & $194-389$ \\
Change in macular volume $\left(\mathrm{mm}^{3}\right)$ & \\
$\quad$ Mean & 3.18 \\
$95 \% \mathrm{Cl}$ for mean $P<0.05$ & $1.04-5.33$ \\
Gain in lines of vision & 3.91 \\
Mean & $3.34-4.49$ \\
$95 \% \mathrm{Cl}$ for mean $P<0.05$ & \\
Duration to resolution of subretinal fluid (months) & 3.58 \\
Mean & $2.73-4.6 \mathrm{I}$ \\
$95 \% \mathrm{Cl}$ for mean $P<0.05$ & \\
\hline
\end{tabular}

One of the patients had CSCR in both the eyes (Figure 1). The symptoms had persisted for 11 months. Right eye (CMT $394 \mu \mathrm{m}$, MV $11.4 \mathrm{~mm}^{3}$, VA 0.77 $\log$ MAR) was associated with a pigment epithelial detachment (PED) and was more severe than left eye (CMT 295 $\mu \mathrm{m}, \mathrm{MV} 9.9 \mathrm{~mm}^{3}$, VA $\left.0.77 \log \mathrm{MAR}\right)$. The right was treated with subthreshold parameters. At 1 month, CSCR had completely resolved in the right eye with persistent PED. The left eye had worsened (CMT $403 \mu \mathrm{m}$, MV $10.4 \mathrm{~mm}^{3}$, and VA $0.77 \log$ MAR) and was treated with subthreshold green laser. At 5-month follow-up, both eyes have complete resolution of the NSD with the disappearance of PED from right eye.

One of the other patient who was kept in observation developed PED and worsening of the CSCR. The involved eye (left) had baseline parameters of CMT $846 \mu \mathrm{m}$, MV $22.6 \mathrm{~mm}^{3}$ (largest MV of treatment group), and VA 1.17 logMAR at the time of treatment. At 5 months, the patients had complete resolution of the CSCR and PED (CMT $173 \mu \mathrm{m}$, MV $9.3 \mathrm{~mm}^{3}$, VA $0.17 \log \mathrm{MAR}$ ) (Figure 4).

There was no relapse of CSCR among patients who had complete resolution of the NSD until the last follow-up. All the cases had complete resolution of the NSD except one. The patient had CMT of $939 \mu \mathrm{m}$ (highest CMT of the treatment group) with MV of $18.4 \mathrm{~mm}^{3}$ with baseline vision of $1.17 \mathrm{log}$ MAR (Figure 2). Following single treatment and follow-up at 5 months, the patient had visual acuity of $0.30 \log$ MAR with CMT of $282 \mu \mathrm{m}$ and MV of $11 \mathrm{~mm}^{3}$. Despite having a gain of 4.4 lines of vision, the patient still had residual fluid. The patient was counseled for a possible second session of laser therapy but denied to receive further treatment due to the "acceptable level" of vision at present (Figure 2).

\section{Discussion}

CSCR is mostly a self-limiting condition. In most cases, reattachment of the NSD occurs within 4 months. Due to this favorable outcome, observation still remains as the firstline approach for its management. Reoccurrences have been reported in $\sim 20 \%-50 \%$ of patients by 1 year and chronic NSD often leads to permanent loss of visual functions. ${ }^{8-10}$ In such cases, active treatment is mandated whenever symptoms or signs persist for $>3$ months. ${ }^{25}$

Various studies have reported successful treatment of chronic CSCR using subthreshold micropulse laser. ${ }^{16,17,26,27}$ Subthreshold lasers are thought to stimulate and enhance healing response of RPE - hence improving pumping and barrier action of RPE. ${ }^{25,28}$ All of them have used VA and changes on SD-OCT as parameters to evaluate response to laser therapy, so we adopted same parameters for easier comparison. Our study demonstrates a dramatic improvement in both anatomical and functional aspect with a single session of green subthreshold laser treatment. All the patients who were selected and treated were under observation for a minimum period of 3 months from the diagnosis. The improvement shown after intervention in gain in VA, reduction in CMT, and MV was statistically significant. Interestingly, one of the patients with bilateral chronic CSCR was initially treated in the worse eye, which showed improvement at follow-up while the other eye worsened. The other eye was then treated - which also showed significant improvement at the next follow-up - which was convincing that improvement was secondary to laser therapy.

Lanzetta et $\mathrm{al}^{17}$ reported two-thirds of their cases had complete resolution of NSD at months, increasing to nearly $75 \%$ at 2 months with the use of $810 \mathrm{~nm}$ diode micropulse laser. We have used the green subthreshold laser for the treatment of chronic CSCR and have reported its results. We found no literature on the use of a green subthreshold laser for CSCR in PubMed-/Medline-indexed journals. We followed up our patients at the end of 5 months, and 12 (92\%) of the 13 eyes had complete resolution of NSD. The larger success number could be due to longer follow-up duration in our patients.

In another study by Ricci et al, ${ }^{29}$ they reported complete resolution of the NSD in five patients and reduction in two of their patients - again with the use of an $810 \mathrm{~nm}$ diode. Only one of the eyes in our series had persistent NSD at the end of 5 months. The patient had the highest CMT in our series with $939 \mu \mathrm{m}, \mathrm{MV}$ of $18.4 \mathrm{~mm}^{3}$ with baseline vision of $1.17 \log$ MAR. At 5 months, the patient had visual acuity 
Macula thickness OU: macular cube $512 \times 128$
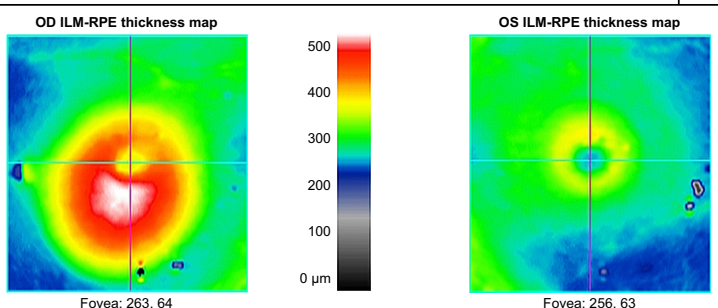

4

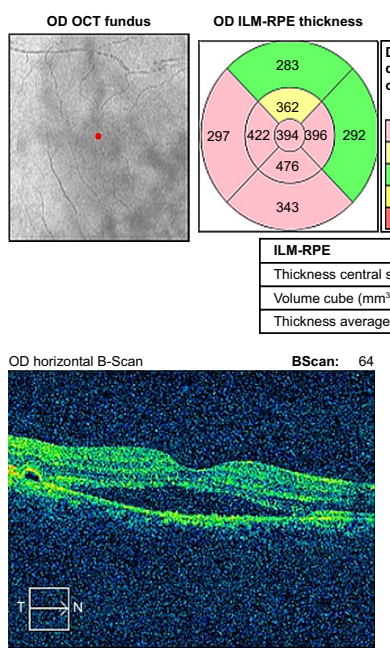

OS ILM-RPE thickness

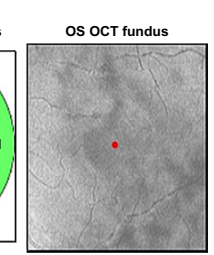

\begin{tabular}{|l|l|}
\hline OD & Os \\
\hline
\end{tabular}

\begin{tabular}{|c|c|}
\hline 394 & 295 \\
\hline 11.4 & 9.9 \\
\hline 316 & 276 \\
\hline
\end{tabular}

OS horizontal B-Scan BScan:

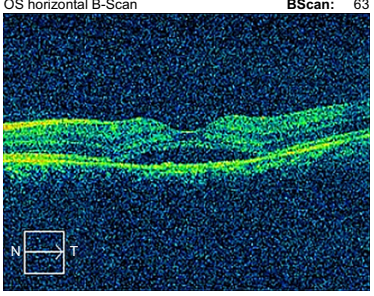

OD $\bullet$ OOS

Macula thickness: macular cube $512 \times 128$
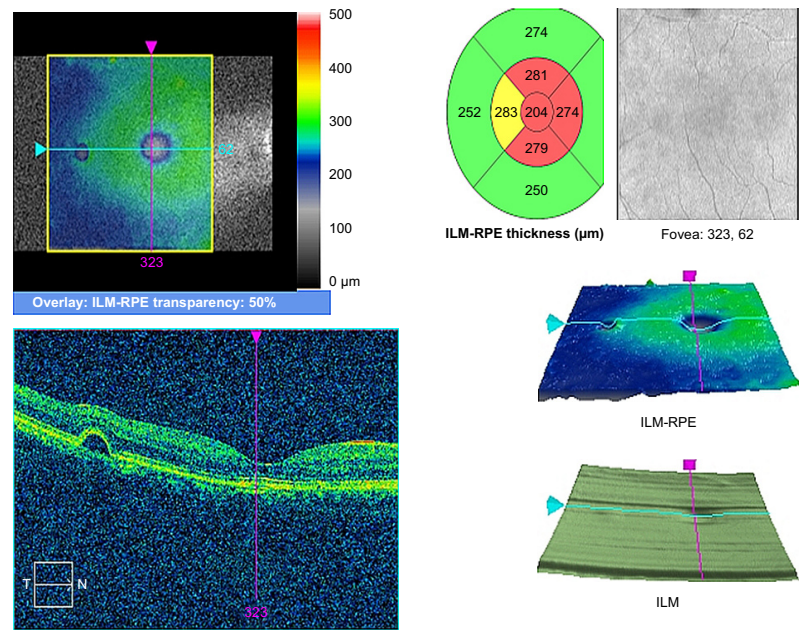

ILM-RPE

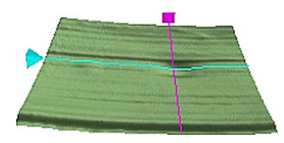

ILM
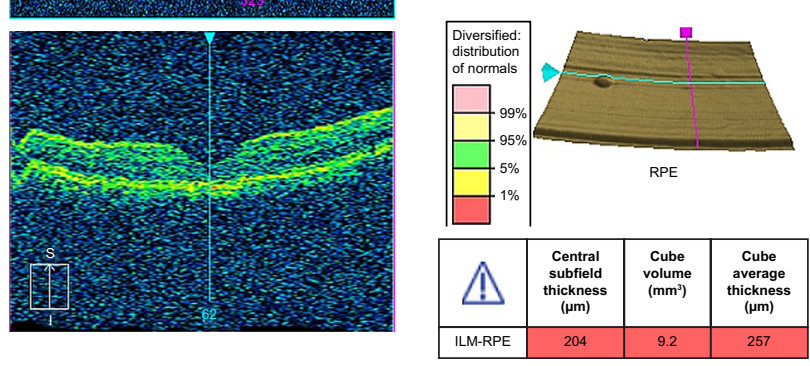

Macula thickness OU: macular cube $512 \times 128$ OD
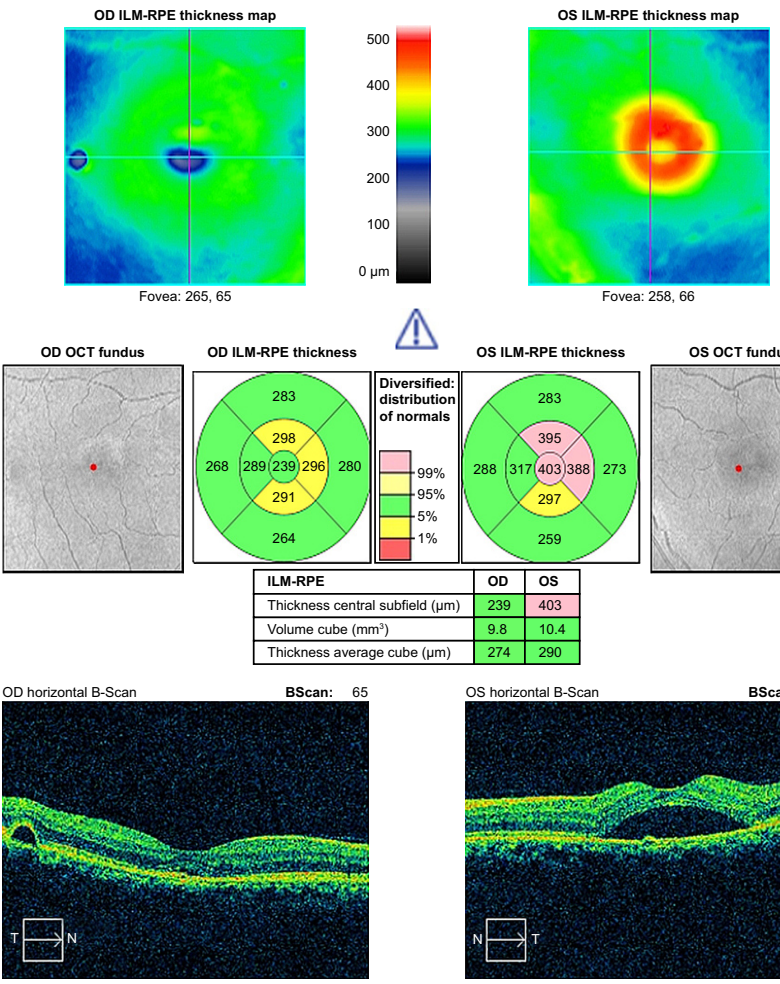

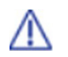

OS ILM-RPE thickness
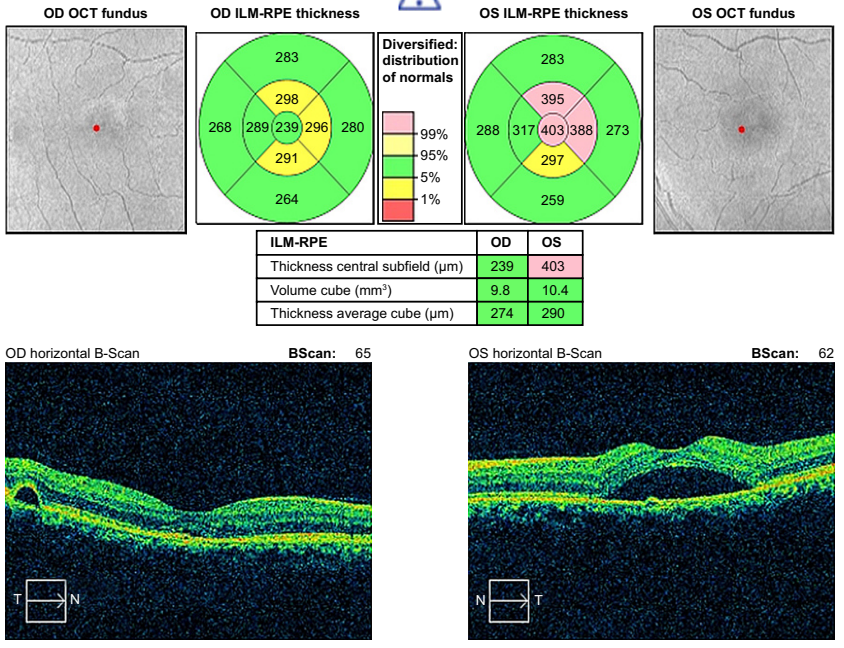

Macula thickness OU: macular cube $512 \times 128$ OD $\bigcirc$
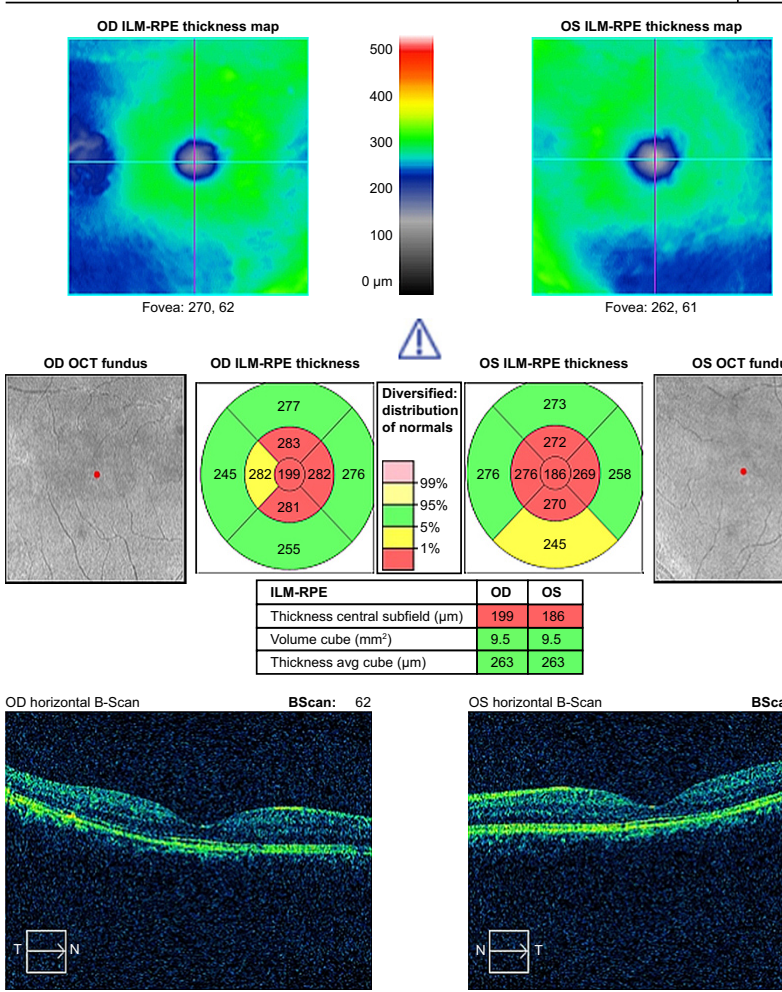

Fvea: 262,61

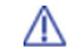

OS ILM-RPE thickness

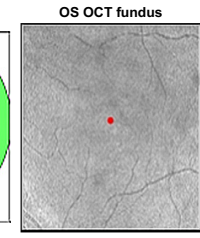

M-RPE

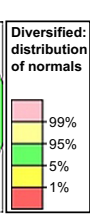

\section{2}
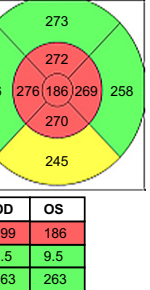

Os horizontal B-Scan

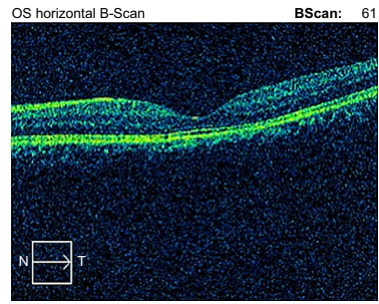

Figure I OCT of the patient with bilateral CSCR at the time of presentation.

Notes: (Top left) Right eye was treated first. Note the improvement in the right eye (top right) and worsening in the untreated (left) eye at first follow-up. Patient received treatment in the left eye. The CSCR resolved in both the eyes and the PED in the right eye also disappeared (bottom left and bottom right).

Abbreviations: CSCR, central serous chorioretinopathy; OCT, optical coherence tomography; PED, pigment epithelial detachment; RPE, retinal pigment epithelium. 

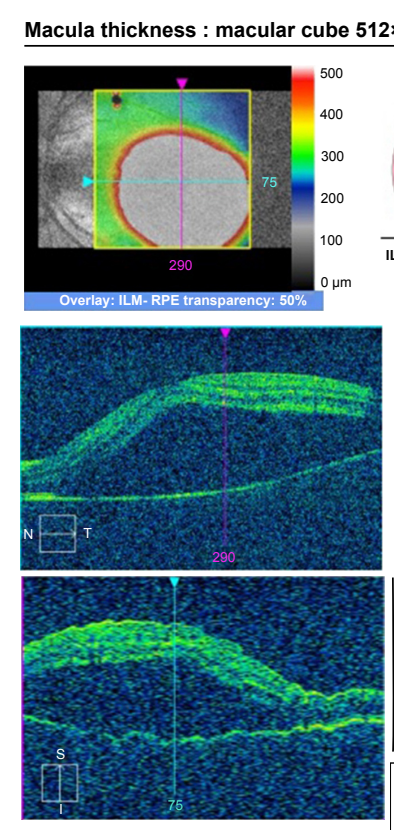

OD O
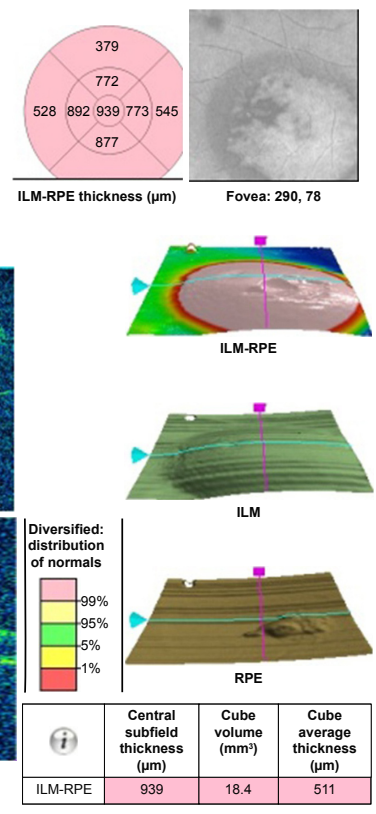

Macula thickness : macular cube $512 \times 128$
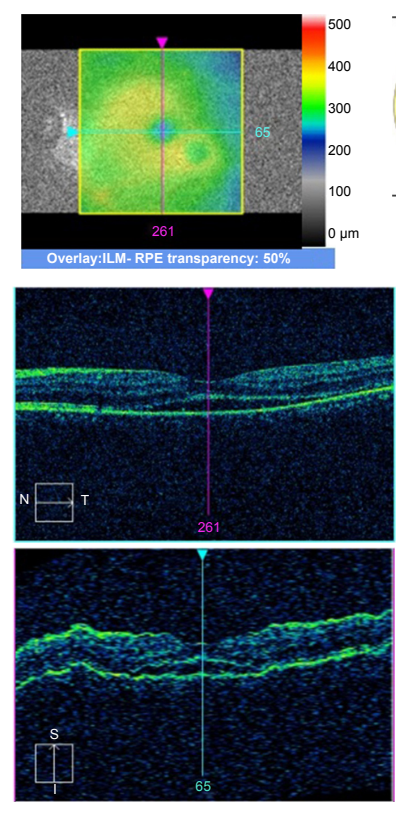

OD O $1 \circ$ OS
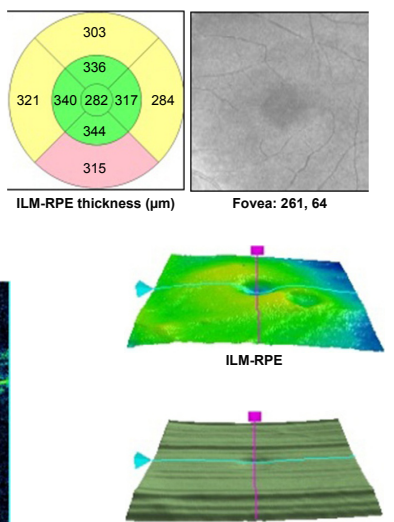

ILM

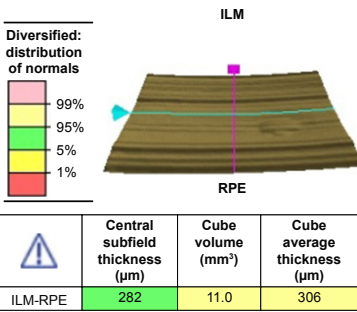

Figure 2 Only one patient did not have a complete resolution of the subretinal fluid at 5-month follow-up following laser treatment.

Notes: The CMT at presentation $(939 \mu \mathrm{m})$ - highest in our series. This however decreased by over $700 \mu \mathrm{m}$ following single treatment. Patient has BCVA of 0.30 logMAR with vision gain of 4.4 lines.

Abbreviations: BCVA, best-corrected visual acuity; CMT, central macular thickness; RPE, retinal pigment epithelium.

of $0.30 \log$ MAR with CMT of $282 \mu \mathrm{m}$ (SRF $\sim 37 \mu \mathrm{m})$ and MV of $11 \mathrm{~mm}^{3}$ and vision gain of 4.4 lines, which was still plausible after a single session of therapy.

Chen et $\mathrm{a}^{16}$ reported that response was elicited in $25 \%$ of the cases with a gain of visual acuity of 3 lines or more being achieved in 15 eyes $(57.7 \%)$ with the use of diode laser. In our study, 12 (92\%) had vision gain of $>3$ lines with one (8\%) case having a gain of 2.7 lines.

Yadav et $\mathrm{a}{ }^{15}$ have reported the use of yellow $(577 \mathrm{~nm})$ subthreshold laser for the treatment of chronic CSCR.
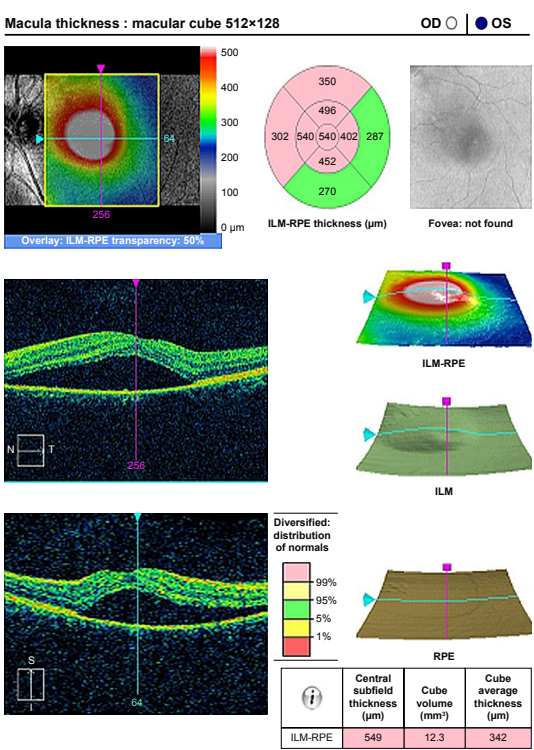
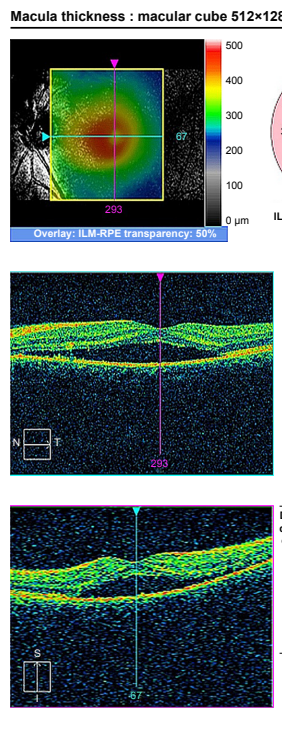

$\mathrm{ODO} \mid \bullet \mathrm{OS}$
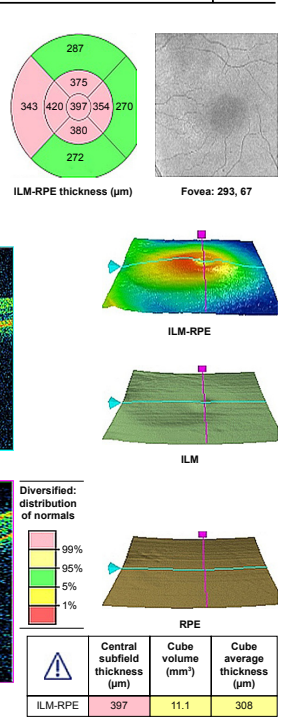
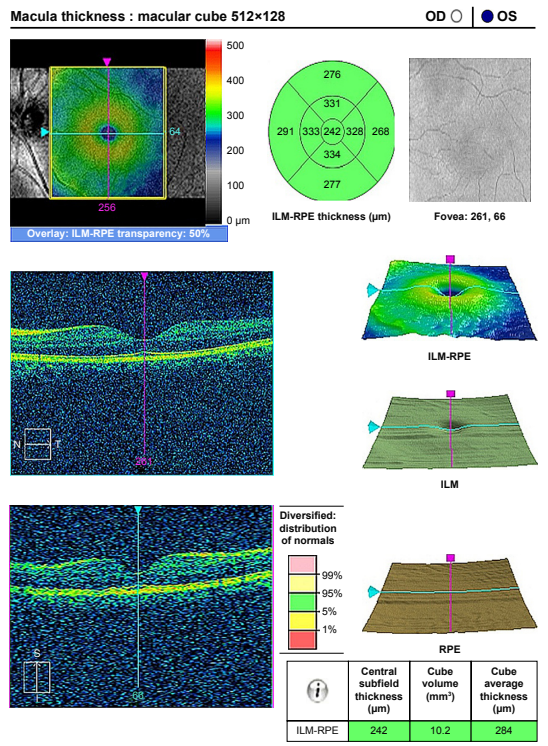

Figure 3 OCT image of the patient showing subsequent decrease in the subretinal fluid and complete resolution at 5 months following single session of laser treatment. Abbreviations: OCT, optical coherence tomography; RPE, retinal pigment epithelium. 
Macula thickness OU: macular cube $512 \times 128$

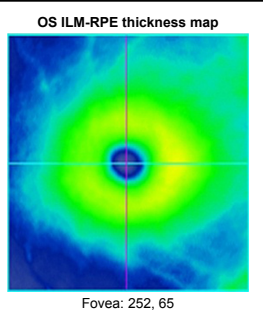

Fovea: 252, 65

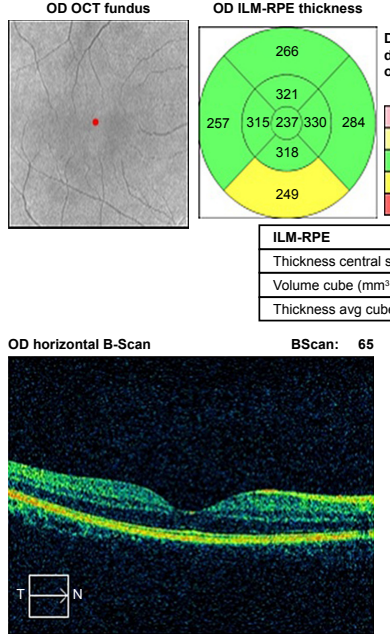

$\Lambda$

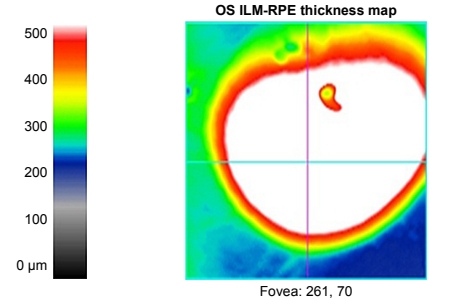

Fovea: 261,70

OD ILM-RPE thickness $\quad$ OS OCT fundus

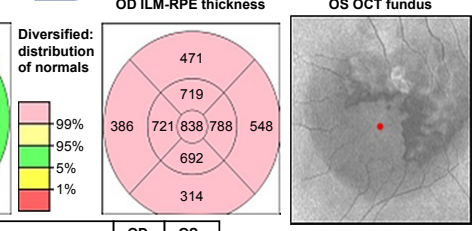

OD

\begin{tabular}{|l|l|}
\hline 9.7 & 16.7 \\
\hline 269 & 463 \\
\hline
\end{tabular}

os horizontal B-Scan
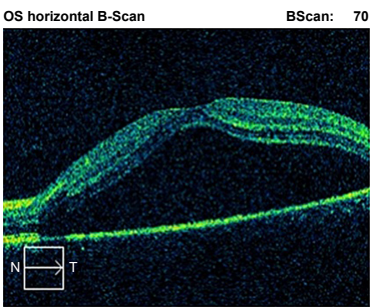

Macula thickness OU: macular cube $512 \times 128 \quad$ OD $\bullet \mid \bullet$ OS

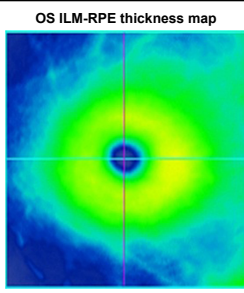

Fovea: 253,64

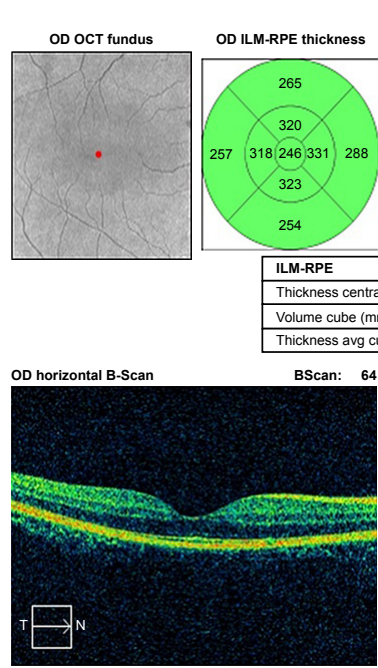

OS ILM-RPE thickness map

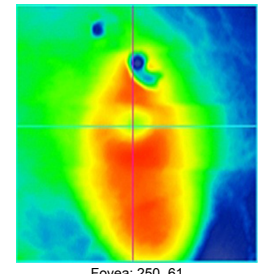

Fovea: 250,61

$\Lambda$

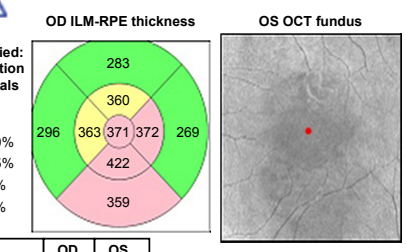

OD 1 OS

\begin{tabular}{|l|l|}
\hline 9.7 & 11 \\
\hline 271 & 306 \\
\hline
\end{tabular}

os horizontal B-Scan

BScan: 61

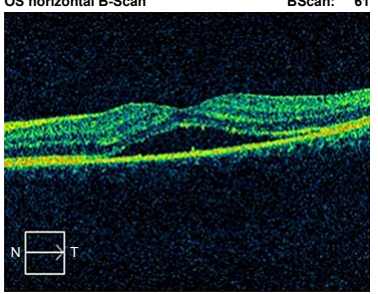

$\frac{\text { Macula thickness OU: macular cube } 512 \times 128 \quad \text { OD }}{\text { os ILM-RPE thickness map }}$

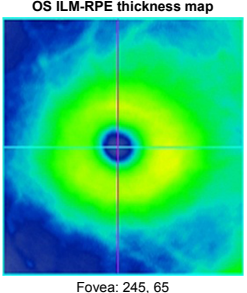

Fovea: 245,65
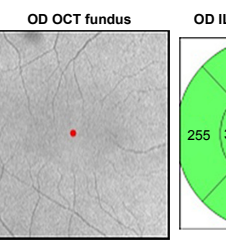

ILM-RPE thickness

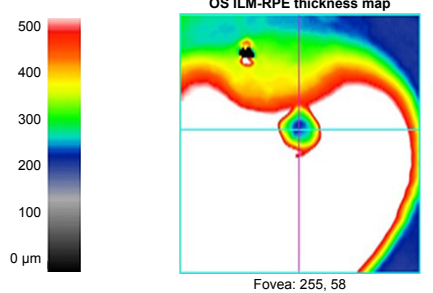

OD ILM-RPE thickness

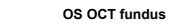

Diversified
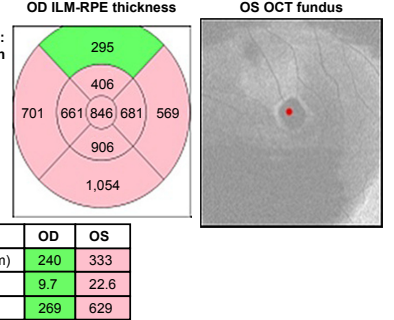

\begin{tabular}{|l|l|l|}
\hline ILM-RPE & OD & OS \\
\hline Thickness central subfield $(\mu \mathrm{mm})$ & 240 & 333 \\
\hline Volume cube $\left(\mathrm{mm}^{3}\right)$ & 9.7 & 22.6 \\
\hline Thickness avg cube $(\mu \mathrm{\mu m})$ & 269 & 629 \\
\hline
\end{tabular} BScan: 65

os horizontal B-Scan BScan: 58
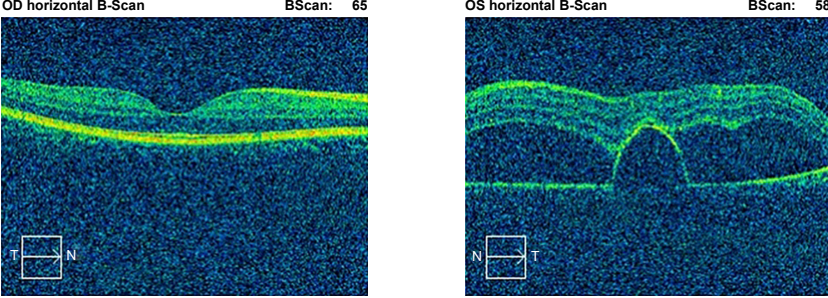

Macula thickness: mascular cube $512 \times 128 \quad$ OD $\bigcirc \mid \bigcirc$ OS
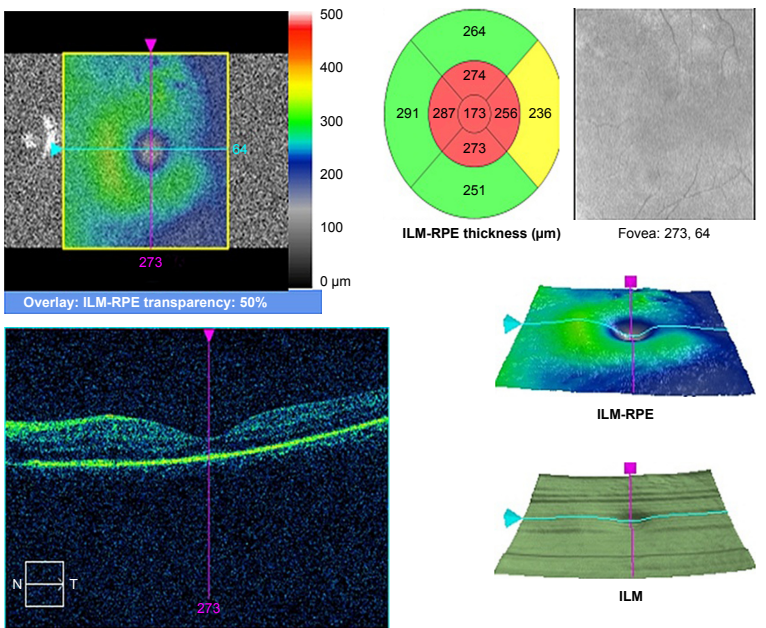

ILM-RPE

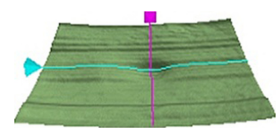

ILM
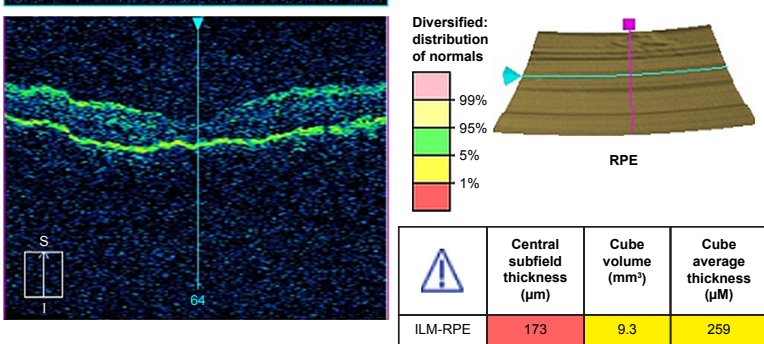

Figure 4 OCT image of the patient kept on observation.

Notes: (Top left) On follow-up, the patient presented with PED and worsening of CSCR (top right). Patient was treated with subthreshold green laser. Baseline parameters were CMT $846 \mu \mathrm{m}, \mathrm{MV} 22.6 \mathrm{~mm}^{3}$ (largest MV of treatment group), and VA 1.17 logMAR. At subsequent follow-up (bottom left) and at 5 months (bottom right), the patient had complete resolution of the CSCR and PED.

Abbreviations: CSCR, central serous chorioretinopathy; MV, macular volume; OCT, optical coherence tomography; PED, pigment epithelial detachment; RPE, retinal pigment epithelium. 
They have reported an average decrease in fluid height by $182 \mu \mathrm{m}(P<0.001)$ at a mean follow-up of 8 weeks. We have not measured fluid height in all our cases. So we have used a decrease in the CMT as a parameter to compare as we believe any decrease in this would correspond to a decrease in fluid height. Our patients had a mean decrease of CMT by $292 \mu \mathrm{m}(95 \% \mathrm{CI}: 194-389, P<0.05)$. They have also reported that the mean pretreatment VA of their patient was $0.301 \log \mathrm{MAR}$ with mean post-treatment VA increasing to 0.17 . The mean BCVA in our patient at pretreatment was 0.96 logMAR (95\% CI: 0.86-1.06, $P<0.05)$ improving to mean BCVA of 0.18 (95\% CI: $0.12-0.23, P<0.05)$, signifying that even though our patients had worse initial VA at baseline the final outcome was almost comparable.

Two of our patients had CSCR associated with PED. After treatment, both the patients showed complete resolution of PED at 5 months, hence denoting that green subthreshold lasers may also be helpful in the management of PED.

\section{Limitations}

Our limitation is a small sample size. We also did not perform FA for evaluation of residual leakages at 5 months. We mostly used SD-OCT and retinal maps for evaluation of probable leak points and its response to therapy at follow-ups.

\section{Conclusion}

Subthreshold green laser (532 nm) is a safe and effective modality for the treatment of chronic CSCR with very good and stable outcomes. It may also be beneficial in the treatment of PEDs. The results are comparable with the other spectrums of a wavelength that are used. The green laser may also enhance the resolution of PED and may also be used safely in its treatment. However, a larger number, longer follow-ups, and comparison with lasers of other wavelengths are mandated.

\section{Acknowledgment}

We would like to thank Mr Mahesh Aryal, senior technical staff for performing the OCT in our patients.

\section{Author contributions}

All authors made substantial contributions to conception and design, acquisition of data, or analysis and interpretation of data; took part in drafting the article or revising it critically for important intellectual content; gave final approval of the version to be published; and agree to be accountable for all aspects of the work.

\section{Disclosure}

The authors report no conflicts of interest in this work.

\section{References}

1. Gass JD. Pathogenesis of disciform detachment of the neuroepithelium. Am J Ophthalmol. 1967;63(3):1-139.

2. Marmor M. On the cause of serous detachments and acute central serous chorioretinopathy. Br J Ophthalmol. 1997;81(10):812-813.

3. Garg SP, Dada T, Talwar D, Biswas NR. Endogenous cortisol profile in patients with central serous chorioretinopathy. $\mathrm{Br} J$ Ophthalmol. 1997;81(11):962-964.

4. Shah SP, Desai CK, Desai MK, Dikshit RK. Steroid-induced central serous retinopathy. Indian J Pharmacol. 2011;43(5):607-608.

5. Daruich A, Matet A, Dirani A, et al. Central serous chorioretinopathy: recent findings and new physiopathology hypothesis. Prog Retin Eye Res. 2015;48:82-118.

6. Liew G, Quin G, Gillies M, Fraser-Bell S. Central serous chorioretinopathy: a review of epidemiology and pathophysiology. Clin Exp Ophthalmol. 2013;41(2):201-214.

7. Wang M, Munch IC, Hasler PW, Prünte C, Larsen M. Central serous chorioretinopathy. Acta Ophthalmol. 2008;86(2):126-145.

8. Gilbert CM, Owens SL, Smith PD, Fine SL. Long-term follow-up of central serous chorioretinopathy. Br J Ophthalmol. 1984;68(11): 815-820.

9. Loo RH, Scott IU, Flynn HW, et al. Factors associated with reduced visual acuity during long-term follow-up of patients with idiopathic central serous chorioretinopathy. Retina. 2002;22(1):19-24.

10. Bujarborua D. Long-term follow-up of idiopathic central serous chorioretinopathy without laser. Acta Ophthalmol Scand. 2001; 79(4):417-421.

11. Su D, Hubschman JP. A review of subthreshold micropulse laser and recent advances in retinal laser technology. Ophthalmol Ther. 2017; 6(1):1-6.

12. do JL, Olmos de Koo LC, Ameri H. Atypical chronic central serous chorioretinopathy with cystoid macular edema: therapeutic response to medical and laser therapy. J Curr Ophthalmol. 2017;29(2):133-135.

13. Tekin K, Ozdamar Erol Y, Yasin Teke M, et al. Cystoid retinal degeneration in chronic central serous chorioretinopathy: a rare optical coherence tomography finding. Int J Ophthalmic Res. 2016;2(1):117-123.

14. Chan WM, Lai TY, Lai RY, Tang EW, Liu DT, Lam DS. Safety enhanced photodynamic therapy for chronic central serous chorioretinopathy: one-year results of a prospective study. Retina. 2008;28(1):85-93.

15. Yadav NK, Jayadev C, Mohan A, et al. Subthreshold micropulse yellow laser $(577 \mathrm{~nm})$ in chronic central serous chorioretinopathy: safety profile and treatment outcome. Eye. 2015;29(2):258-265.

16. Chen SN, Hwang JF, Tseng LF, Lin CJ. Subthreshold diode micropulse photocoagulation for the treatment of chronic central serous chorioretinopathy with juxtafoveal leakage. Ophthalmology. 2008; 115(12):2229-2234.

17. Lanzetta P, Furlan F, Morgante L, Veritti D, Bandello F. Nonvisible subthreshold micropulse diode laser $(810 \mathrm{~nm})$ treatment of central serous chorioretinopathy. A pilot study. Eur J Ophthalmol. 2008;18(6): 934-940.

18. Roisman L, Magalhães FP, Lavinsky D, et al. Micropulse diode laser treatment for chronic central serous chorioretinopathy: a randomized pilot trial. Ophthalmic Surg Lasers Imaging Retina. 2013;44(5): 465-470.

19. Malik KJ, Sampat KM, Mansouri A, Steiner JN, Glaser BM. Lowintensity/high-density subthreshold microPulse diode laser for chronic central serous chorioretinopathy. Retina. 2015;35(3):532-536.

20. Mainster MA. Laser-tissue interactions: future laser therapies. In: Diabetic Retinopathy: Approaches to a Global Epidemic. Association for Research in Vision and Ophthalmology Summer Research Conference; July 31, 2010; Natcher Center, National Institutes of Health, Bethesda, MD. 
21. Mainster MA. Decreasing retinal photocoagulation damage: principles and techniques. Semin Ophthalmol. 1999;14(4):200-209.

22. Yadav NK, Jayadev C, Rajendran A, Nagpal M. Recent developments in retinal lasers and delivery systems. Indian J Ophthalmol. 2014;62(1): $50-54$.

23. Brinkmann R, Roider J, Birngruber R. Selective retina therapy (SRT): a review on methods, techniques, preclinical and first clinical results. Bull Soc Belge Ophtalmol. 2006;302:51-69.

24. Topcon. Endpoint management: Non-damaging laser therapy of the macula. Tokyo: Topcon Corporation; November/December 2015. Available from: http://retinatoday.com/pdfs/1215_insert3.pdf. Accessed September 20, 2018.

25. Robertson DM, Ilstrup D. Direct, indirect, and sham laser photocoagulation in the management of central serous chorioretinopathy. Am J Ophthalmol. 1983;95(4):457-466.
26. Gupta B, Elagouz M, Mchugh D, Chong V, Sivaprasad S. Micropulse diode laser photocoagulation for central serous chorio-retinopathy. Clin Exp Ophthalmol. 2009;37(8):801-805.

27. Koss MJ, Beger I, Koch FH. Subthreshold diode laser micropulse photocoagulation versus intravitreal injections of bevacizumab in the treatment of central serous chorioretinopathy. Eye. 2012;26(2): $307-314$.

28. Verma L, Sinha R, Venkatesh P, Tewari HK. Comparative evaluation of diode laser versus argon laser photocoagulation in patients with central serous retinopathy: a pilot, randomized controlled trial [ISRCTN84128484]. BMC Ophthalmol. 2004;4:15.

29. Ricci F, Missiroli F, Regine F, Grossi M, Dorin G. Indocyanine green enhanced subthreshold diode-laser micropulse photocoagulation treatment of chronic central serous chorioretinopathy. Graefes Arch Clin Exp Ophthalmol. 2009;247(5):597-607.
Clinical Ophthalmology

\section{Publish your work in this journal}

Clinical Ophthalmology is an international, peer-reviewed journal covering all subspecialties within ophthalmology. Key topics include: Optometry; Visual science; Pharmacology and drug therapy in eye diseases; Basic Sciences; Primary and Secondary eye care; Patient Safety and Quality of Care Improvements. This journal is indexed on

Submit your manuscript here: http://www.dovepress.com/clinical-ophthalmology-journal

\section{Dovepress}

PubMed Central and CAS, and is the official journal of The Society of Clinical Ophthalmology (SCO). The manuscript management system is completely online and includes a very quick and fair peer-review system, which is all easy to use. Visit http://www.dovepress.com/ testimonials.php to read real quotes from published authors. 